\title{
A programmatic approach Systematically tying the library to student retention efforts on campus
}

$\mathbf{R}$ egardless of your institution's size, demographics, or mission, student retention is an unavoidably hot topic. As Megan Oakleaf states in the ACRL Value of Academic Libraries report, "student retention and graduation rates are currently among the most discussed foci of institutional missions." ${ }^{\text {Recent }}$ pressure from the Obama administration and accrediting bodies has resulted in a hyper-focus on assessment to demonstrate gains in student success. Meanwhile, libraries are still struggling to distance themselves from a culture of soft-assessment that leaves them unprepared for these new expectations. Along with reconfiguring assessment, exploring more nebulous contributing factors to student success might help propel measurement forward. An example of this includes considering student relationships with the library and staff, as well as acculturation on campus, as these are accepted as factors influencing student success and retention. ${ }^{2}$ These factors are in the realm of the affective domain of learning, and can be classified under one of three distinctions from Bloom's Taxonomy of Learning Domains that "focus on feelings, values, and attitudes." ${ }^{\prime 3}$ Considering the effect of relationships and emotions on student success, creating a more meaningful library experience for students may help improve engagement. Brian Mathews discusses creating experiential connections for students to improve attitudes and feelings about the library:

Let's link the library to feelings of accomplishment rather than to collections. Let's play the empathetic card, rather than the info lit one. Let's build upon mystery and serendipity to counter intimidation and anxiety. Let's employ engagement practices rather than a purely task-oriented appeal. $^{4}$

Other difficulties in developing and assessing initiatives tied to the library's role in student retention relate to measuring programmatic efforts. Programmatic approaches tend to be more effective, yet are difficult to coordinate with retention efforts divvied up among numerous units. Furthermore, many librarians are often hesitant to collect data on their users, for fear of violating student privacy. Now is the time for librarians to proactively begin to develop the campus relationships and collaborations that can lead to improved student success. These beginnings vary, as each institution has its own unique culture and opportunities for library integration. In this article, we discuss some of the opportunities we've pursued as examples of how institutional initiatives can be leveraged to measurably improve library impact on student persistence and retention.

\section{Naugatuck Valley Community College (NVCC)}

NVCC has had a first-year experience program for several years, but in the fall of 2012, library

Nicole Pagowsky is instructional services librarian at the University of Arizona, e-mail: pagowskyn@u.library. arizona.edu, and Jaime Hammond is reference and outreach librarian at Naugatuck Valley Community College, e-mail: jhammond@nvcc.commnet.edu

() 2012 Nicole Pagowsky and Jaime Hammond 
instruction sessions will become mandatory. As a result, the library staff will have the opportunity to assess the information literacy of incoming students. This is both a thrilling and frightening prospect, as this type of direct assessment has not been done before. Students will be asked to answer a series of iClicker questions relating to class outcomes, which have been developed out of the ACRL Information Literacy Competency Standards for Higher Education. We believe the data from approximately 1,000 students ( $\sim 28$ students x 34 sections) will establish a solid baseline of incoming students' information literacy comprehension. Using this baseline, we hope to track student success and, through subsequent assessments, tie student exposure to the library and mastery of information literacy objectives to student retention. Fortitude will be key, however, as this goal will require numerous workflow changes, consistent monitoring of methods, and will not result in solid evidence for two to six years (the typical length of study for community college students).

Having the potential to reach every firsttime, full-time student will affect the rest of our information literacy program. Whereas before, our instruction sessions were based on faculty request and were scattershot in coverage, now the majority of the first time, full-time students will have been exposed to basic information literacy skills before they visit the library in their introductory-level English classes. This obviously changes our approach to those English classes, but how? Projects such as Claremont Colleges Library Curriculum Mapping, ${ }^{5}$ led by Char Booth, are using concept mapping to visually represent program requirements and curriculum to identify opportunities for librarians to support and enhance learning. Plans are in process to experiment with Booth's model to map student learning outcomes in first-year experience and introductory-level English classes to best identify appropriate information literacy outcomes and avoid repetition.

While we are concentrating efforts on introducing first-time, full-time students to information literacy skills, we are also taking advantage of another new project at NVCC. The Honors Program, comprised of honors courses and "honors-by-contract" individualized research projects within regular classes, was trialed in the spring of 2012 and began officially this fall. Working with honors students is an easy win for the library, as there is a strong relationship between high achievers and library use. ${ }^{6}$ Along with faculty, librarians are a prime resource for any individualized research project. Aiming to work with honors-by-contract students as soon as they begin their projects, we plan to meet with students individually to help focus research skills and proactively procure necessary materials. Additional outreach to honors students will include an honors-only reserved time in the library's group study area and student poster sessions hosted by the library. These student/librarian relationships are an important contribution to a student's sense of belonging, academic success, and connection with those who support success - all of which contribute directly to student retention.

\section{The University of Arizona (UA)}

The Arizona Board of Regents has identified improvement in student retention as a key metric for state funding, with a goal of improving freshmen retention and raising six-year graduation rates by five percentage points each. As such, it is critical that the UA Libraries take advantage of opportunities to have a demonstrable impact in these areas. Ensuring our efforts "scale" is also critical, due to the size of the campus and the limited library FTE. Toward this goal, we have focused on becoming embedded in established or developing programmatic efforts and taking a "train-the-trainer" approach for nonlibrary staff engaged in retention. These approaches have also helped us build more collaborative relationships with units across campus, focusing on units supporting high-risk and high succeeding students. These include our athletes' instructional support center, the Honors College, multicultural centers, and the campus tutoring center. We feel that these kinds of long-term relationships give us a better chance to assess and demonstrate our value as efficiently and effectively as possible: rather than hitting the same students with the 
same content multiple times, these relationships make it possible to reach a variety of groups at point-of-need.

At UA, Student Affairs is a major player in campus-wide retention initiatives, and many of the collaborations we have established have been with this unit. We deliver a training session for academic advisors and tutors who work solely with student athletes, updating them on the services and resources the library offers, as well as providing a refresher on searching library databases. This training helps them answer students' questions about research and also results in them referring more students to the library for further assistance. We are also using this model with the campus tutoring center, where library instruction sessions are being incorporated into training for learning specialists who work with students on academic probation.

The Dean of Students Office offers faculty that have found students in their classes plagiarizing, whether intentionally or not, the option to send them to a mandatory academic integrity workshop instead of possible expulsion. This option has resulted in more faculty reporting students, which gives students the opportunity to learn from their mistakes, and doesn't negatively impact student retention. The UA Libraries has an established role in this multisession workshop- to teach students how to properly cite sources and how to employ strategies and use library resources to avoid unintended plagiarism. Assessments of these sessions have shown that even if students first attend reluctantly, they ultimately find the experience valuable and have even suggested the workshop should be required of all students.

Another higher-level link to improving retention campuswide is through Student Affairs' new Early Alert tool, connecting academic advisors to students at risk, providing them with a support network early in their college career. UA's Early Alert is similar to other data mining and e-advising software used in academia. Marc Parry explains this big data software in his New York Times article, "[t]he new breed of software can predict how well students will do before they even set foot in the classroom. It recommends courses, Netflix-style, based on students' academic records." Course recommendations are not the only possibility, but also advising support when students might fall at risk. Having advisors be able to refer students to the library, just as they already plan to make referrals to various student services when undergraduates are found to be struggling academically or otherwise, could help the library provide instructional services at point-of-need. Being embedded in these big data tools ties the library more strongly to campus through working systematically to ensure student success, as well as creates a more personalized experience with the library, tying retention to affective outcomes.

A future area of focus for libraries to consider as these big data services increase in prominence is both supplying metrics to demonstrate that library use does have an effect on student success and also providing support through instruction and learning objects for students needing remediation. Ellen Collins in the Library Data Impact Project notes:

Library usage data could be another tool within the armoury of student support services, one part of a complex picture, which helps them to understand which students might be at risk of failing to complete their degree. ${ }^{8}$

This type of systems thinking, where the library is highly connected to the rest of the institution is integral in demonstrating the value of the library and making efforts to support campuswide retention resonate at a larger scale. Emmons and Wilkinson explain systems thinking as looking at "people and units and the relationships between them interacting to form a complex whole."

\section{Conclusion}

It is clear that libraries have the opportunity to play a significant role in the retention of students, whether it is through librarian-student relationships, being embedded, collaborating with support services, or other means; and 
the way this looks at each institution will differ. Learning how to measure success and assess effectiveness in retention initiatives can be tricky, with efforts spread throughout the campus, and it can be difficult to tie these metrics together to show the library's value. Furthermore, assessing causation versus correlation can be problematic from difficulty in ferreting out how much improvement is related to the library and how much is simply high-achieving students being more inclined to use the library and its resources throughout college. This becomes even harder to pin down when trying to measure impacts of tying experience and affect to the library. This is why projects like the ACRL Value of Academic Libraries Report will be invaluable in this work, as well as support networks to share ideas.

We have established a new ACRL Student Retention Discussion Group ${ }^{10}$ to address these gaps and provide librarians working with retention an avenue for sharing information and collaboration. At the ACRL Student Retention Discussion Group's first meeting at the 2012 ALA Annual Conference, we covered what others at different campuses are doing, with systems thinking being used by libraries in some campuses. The role of the library is in campus retention efforts, based on discussion, includes campus partnerships and initiatives; assessment; and measuring success in specific, regular courses. First-year seminars were discussed, as well as reaching out to atrisk student groups, such as bridge programs and athletics.

Our hope is to have a greater arena for trial and error within this discussion group, moving the focus away from just inputs and outputs to actual impact. ${ }^{11}$ With these challenges in mind, we have been making small strides at our libraries to support campus retention efforts and continuing to explore assessment methods.

\section{Notes}

1. Megan Oakleaf, "Value of Academic Libraries," Association of College and Research Libraries, 2009, www.ala.org/acrl/sites/ala.org. acrl/files/content/issues/value/val_report.pdf.
2. Jacqui D. Grallo, Mardi Chalmers, and Pamela G. Baker, "How Do I Get a Campus ID? The Other Role of the Academic Library in Student Retention and Success," Reference Librarian 53, no. 2 (2012): 182-93. doi:10.1080/02763877.20.

3. WikiEducator, "Learning Objectives and Bloom's Taxonomy," last modified June 13, 2008, http://wikieducator.org/Teachers_Without_ Borders/Assessment_Practices/Learning _Objectives_and_Bloom\%E2\%80\%99s _Taxonomy.

4. Brian Mathews, "How Do We Want Students to Feel About the Library?" The Ubiquitous Librarian, last modified March 29, 2012, http://chronicle.com/blognetwork/theubiquitouslibrarian /2012/03/29/how-do-we-want-them-to-feel -about-the-library/.

5. Char Booth, "Project Curve, Part Four: Mapping (Concept to Curriculum)," Info-mational, last modified August 18, 2011, http://infomational.wordpress.com/2011/08/18 /project-curve-part-four-mapping-concept-to -curriculum/.

6. Ying Zhong and Johanna Alexander, "Academic Success: How Library Services Make a Difference," ACRL 13th National Conference Proceedings (Chicago, IL: American Library Association, 2007).

7. Marc Parry, "Big Data on Campus," The New York Times, July 18, 2012, www. nytimes.com/2012/07/22/education/edlife /colleges-awakening-to-the-opportunities-of -data-mining.html?pagewanted=all.

8. Ellen Collins, "Library Usage and Dropping Out," Library Impact Data Project, last modified July 10, 2012, http://library.hud.ac.uk/blogs /projects/lidp/2012/07/10/library-usage-and -dropping-out/.

9. Mark Emmons and Frances C. Wilkinson, "The Academic Library Impact on Student Persistence," CERL 72, no. 2 (2011): 128-49, http:// crl.acrl.org/content/72/2/128.full.pdf+html.

10. ACRL Student Retention Discussion Group may be found at http://connect.ala.org /node/173037.

11. Emmons, "The Academic Library Impact on Student Persistence."

(continues on page 594) 
would be to begin promotion a month before the events and seek aid from your Student Affairs department. Also, when planning events, include the pre-involvement of the campus community much like our 20x20 event. Involving professors and prominent staff in the events encourages a higher turnout, as many students and staff desire to network outside of the normal day-to-day setting.

\section{Assessment and lessons learned}

Ultimately, the value of any library event is assessed by its short-term and long-term impact. In the case of Find Your Place, both were positive. Short-term, the Schusterman Library's new digital gallery received increased awareness after the very successful 20x20 event. The library has already been asked by university staff to host a second 20x20 event. As a result of this greater awareness and interest, more people will visit the library to view the gallery's current exhibits hosted in this space. In addition, this event encouraged participation across campus as OU-Tulsa students, faculty, and staff interacted in an informal environment to share their presentations.

There has also been a positive long-term impact. In preparation for the social media lunch, the library created a Web page highlighting the various social media tools discussed. Another long-term impact was the establishment of the library as a Foursquare destination. Also, letterboxers and geocach- ers, many of whom may have been unfamiliar with OU-Tulsa, now have a reason to visit the campus. As of May 2012, 64 geocachers have signed the logbooks and 8 letterboxers have stamped the letterbox hidden within the library. Therefore, we are continuing to explore and offer new ways for users to interact and communicate with the library.

It is difficult to know when to hold an event. While we chose the first week in October in order to allow students time to become accustomed to their schedules, we may consider hosting these activities earlier in the semester, when new students are still becoming familiar with the campus and library services. Additionally, we will probably condense the events into one full day, scheduling four-to-six events so that attendees can come and go as their time permits. After attending one event they will likely stay for more, as we found that several attendees returned for other events later in the week.

In conclusion, Find Your Place not only introduced the campus community to our new facility, it also gave the library an opportunity to support the institution's strategic goals. Our weeklong series of informal events brought together diverse groups of students, faculty, and staff to interact together within the library. Taking into consideration the successes achieved and lessons learned, we look forward to the planning and implementation of next year's Find Your Place events. $\boldsymbol{n}$

("A programmatic approach" continued from page 585)

\section{Further reading}

ACRL Information Literacy Competency Standards for Higher Education, www.ala.org /acrl/standards/informationliteracycompetency.

Bell, Steven. "Keeping Them Enrolled: How Academic Libraries Contribute to Student Retention." Library Issues 29, no. 1 (2008): np.

Bell, Steven. "The Changing Nature of Student Retention.” ACRL Insider, 2012. www.acrl. ala.org/acrlinsider/archives/5003.

Blackburn, Heidi. "Shhh! No talking about retention in the library!" Education Libraries 33, no. 1 (2010): 24-30.
Community College Survey of Student Engagement (CCSSE). www.ccsse.org/.

Cottrell, Janet. "What are we doing here, anyway? Tying academic library goals to institutional mission." CERL News 72, no.9 (2011): 516-20.

National Survey of Student Engagement (NSSE). http://www.nsse.iub.edu/.

Rhoades, James G. Jr., and Arianne Hartsell. "Marketing First Impressions: Academic Libraries Creating Partnerships and Connections at New Student Orientations." Library Philosophy and Practice (2008): np. www.webpages.uidaho. edu/ mbolin/rhoades-hartsell.htm. $\boldsymbol{n}$ 